\title{
Sophisticated regulation of micturition: review of basic neurourology
}

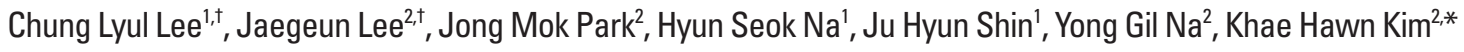 \\ 'Department of Urology, Chungnam National University Hospital, Chungnam National University School of Medicine, Daejeon, Korea \\ ${ }^{2}$ Department of Urology, Chungnam National University Sejong Hospital, Chungnam National University School of Medicine, Sejong, Korea
}

The neurological regulation of the lower urinary tract can be viewed separately from the perspective of sensory neurons and motor neurons. First, in the receptors of the bladder and urethra of sensory nerves, sensations are transmitted through the periaqueductal gray matter of the midbrain to the cerebral cortex, and the cerebrum goes through the process of decision-making. Motor neurons are divided into upper motor neurons (UMNs) and lower motor neurons (LMNs). UMNs coordinate storage and micturition in the brain stem so that synergic voiding can occur. LMNs facilitate muscle contractions in the spinal cord. The muscles involved in urinary storage and micturition are innervated by the somatic branches of sympathetic, parasympathetic, and peripheral nerves. Sympathetic nerves are responsible for contractions of urethral smooth muscles, while parasympathetic nerves originate from S2-S4 and are in charge of contractions of the bladder muscle. Somatic nerves originate from the motor neurons in Onuf's nucleus, which is a specific part of somatic nerves. In this review, we will investigate the structures of the nervous systems related to the lower urinary tract and the regulatory system of innervation for the urinary storage and micturition and discuss the clinical significance and future prospects of neurourological research.

Keywords: Lower urinary tract, Neurourology, Micturition center, Urinary storage

\section{INTRODUCTION}

The urinary storage and periodical micturition are accomplished by the coordinated activities of three functional units: the bladder, which is responsible for the storage of urine; the bladder neck, which is the outlet of the bladder; and the lower urinary tract, which is composed of the urethra and the urethral sphincter. The cooperation between the components of the lower urinary tract is mediated by a complex neural control system in the brain, spinal cord, and peripheral ganglia (de Groat, 2006). Thus, the storage and micturition are closely related to central nervous system pathways.

Axon bundles that run through the spinal cord from the cerebral cortex form the pyramidal tract, which descends and forms the corticospinal tract that runs from the inside of the spinal cord to two pathways: the lateral and anterior or ventral corticospinal tracts. Upper motor neurons (UMNs) have cell bodies located in the motor cortex of the cerebral cortex and axons that travels through the brain stem to the spinal cord. UMNs are distinctive in that they are not in direct contact with muscles. Lower motor neurons (LMNs) connect with UMNs in the spinal cord. While the majority of them are connected via interneurons, a few UMNs and LMNs directly form synapses at the anterior or ventral horn of the spinal cord. When the axons of LNMs exit the spinal cord, they run past the anterior or ventral root (efferent nerve roots), through which motor and autonomic nerves travel, to the neuromuscular plate or neuromuscular junction and are then responsible for voluntary innervation in voluntarily controlled muscles. Onuf's nucleus is a defined group of neurons located in the ventral part of the anterior horn of the sacral spinal cord maintains continence of micturition

This is an Open Access article distributed under the terms of the Creative Commons Attribution Non-Commercial License (https://creativecommons.org/licenses/by-nc/4.0/) which permits unrestricted non-commercial use, distribution, and reproduction in any medium, provided the original work is properly cited.

\footnotetext{
${ }^{*}$ Corresponding author: Khae Hawn Kim (D) https://orcid.org/0000-0002-7045-8004 Department of Urology, Chungnam National University Sejong Hospital, Chungnam National University School of Medicine, 20 Bodeum 7-ro, Sejong 30099, Korea Email:kimcho99@cnuh.co.kr

${ }^{\dagger}$ These authors contributed equally to this study as co-first authors.

Received: September 2, 2021 / Accepted: October 5, 2021
} 
and defecation and causes muscular contraction in response to orgasm. In particular, this group includes motor neurons and forms the origin of the pudendal nerves.

In this review, we will investigate the structures of the peripheral nervous system and central nervous system that are related to the lower urinary tract and the regulatory system of innervation for the urinary storage and micturition.

\section{THE PERIPHERAL NERVOUS SYSTEM OF THE LOWER URINARY TRACT}

The efferent pathway of the lower urinary tract is controlled by three components of the peripheral nervous system: the parasympathetic, sympathetic, and somatic nervous systems. (Fig. 1) The parasympathetic nerve pathway (green) originates from the sacrum (S2-S4) and runs through the pelvic nerves, the ganglion cells of the pelvic plexus, and into the terminal nerve ganglia of the bladder wall and urethra. It releases acetylcholine at nerve endings and acts mainly in response to $\mathrm{M} 3$ muscarinic receptors to contract the bladder. The sympathetic nerve pathway (blue) originates from the thoracolumbar spine (T11-L2) and passes through the intermesenteric plexus and hypogastric nerves into the pelvic plexus and genitourinary organs. It releases noradrenaline at nerve endings, acts in response to $\beta 3$-adrenoceptors of the bladder to relax the bladder, and responds to a1-adrenoceptors of the bladder base and urethra to contract the bladder neck and urethra. The somatic nerve pathway (yellow) originates from the sacrum (S2-S4) and runs through the pudendal nerves to act on the external urinary sphincter. It releases acetylcholine at nerve endings and acts on the nicotinic receptors to contract the external urethral sphincter (EUS) (Fowler et al., 2008).

\section{Parasympathetic nerves}

The parasympathetic nervous system acts to contract the detrusor muscle and relax the urethra. Parasympathetic preganglionic neurons are located in the sacral parasympathetic nucleus (SPN) on the outside of the sacral intermediate gray matter at S2-S4 (de Groat et al., 1996; Nadelhaft et al., 1980). These neurons send axons through the ventral root and release acetylcholine, which travels past the pelvic nerves and connects with the pelvic plexus and postganglionic nerves on the bladder surface, or in the bladder wall and urethra to elicit the normal contraction of the bladder (Andersson, 1993; Andersson and Arner, 2004; Matsui et al., 2000; Matsui et al., 2002). However, detrusor hyperactivity, bladder outlet obstruction, or bladder pain syndrome/interstitial cystitis may show nonadrenergic, noncholinergic bladder contraction,

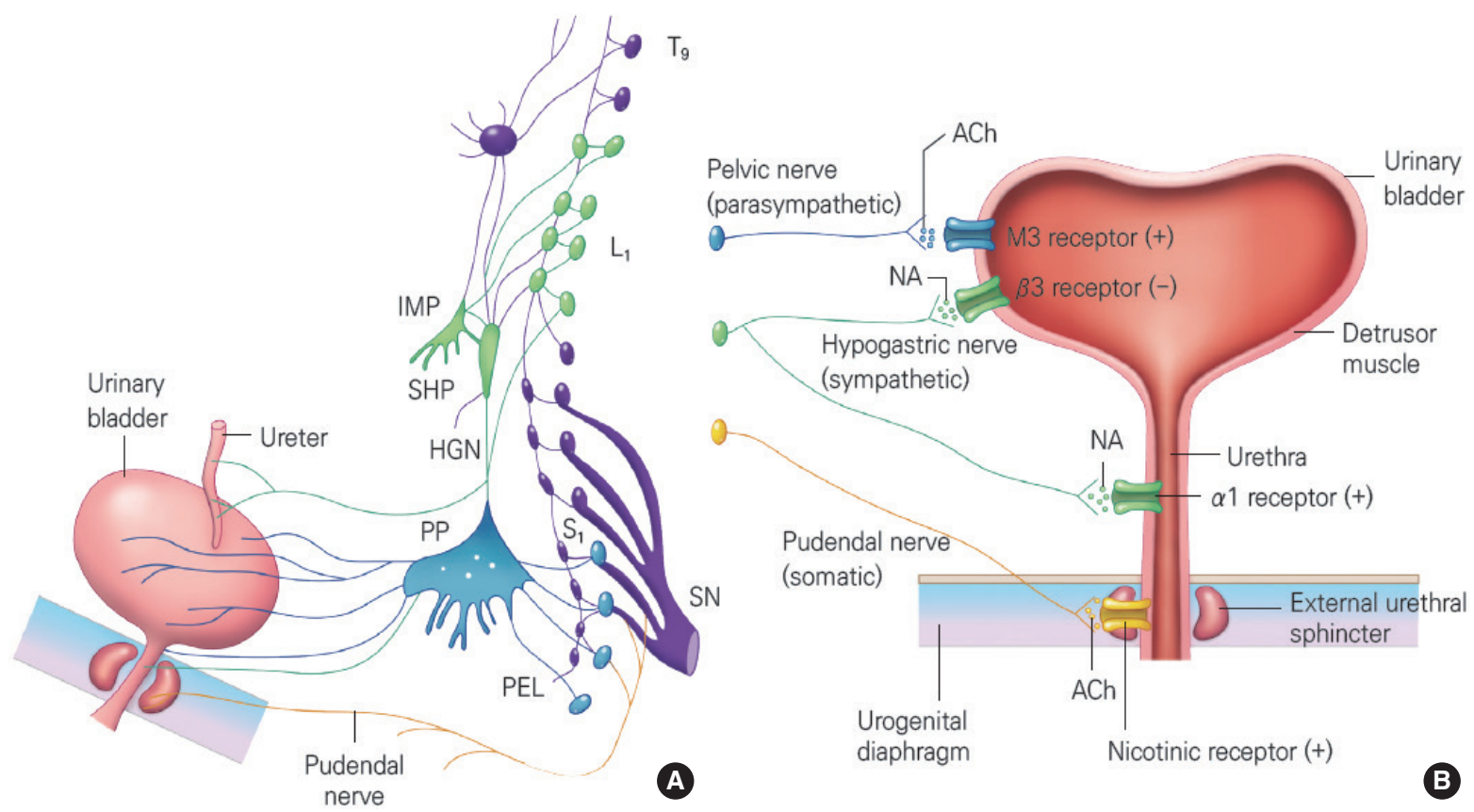

Fig. 1. Efferent pathways of the lower urinary tract in women. Upper motor neuron (A) and lower motor neuron (B). IMP, inferior mesenteric plexus; SHP, superior hypogastric plexus; HGN, hypogastric nerve; PP, pelvic plexus; PEL, pelvic nerve; SN, sacral nerve; ACh, acetylcholine; NA, noradrenaline; M3, muscarinic acetylcholine type-3 receptor; $\alpha 1$, alpha-1-adrenoceptor; $\beta 3$, .beta-3-adrenoceptor. 
in which case adenosine triphosphate acts as the main mediator (Andersson and Wein, 2004; Burnstock, 2001; Palea et al., 1993). The fact that parasympathetic postganglionic neurons are located not only in the pelvic plexus, but also on the detrusor muscle is meaningful in that patients with defects in the cauda equina or pelvic plexus may not be completely denervated even if they are decentralized neurologically. This fact makes it possible for there to be a connection between efferent and afferent neurons at the ganglionic region in the detrusor muscle even in the presence of a defective cauda equina (de Groat et al., 1996).

\section{Sympathetic nerves}

The sympathetic nerves that originate from the thoracolumbar spine (T11-L2) have a relatively complex pathway, running through the sympathetic chain ganglia. Axons from the spinal cord run in the inferior mesenteric ganglia and hypogastric nerves through inferior splanchnic nerves into the pelvic plexus. Sympathetic nerves release noradrenaline into the bladder and urethra to send excitatory and inhibitory signals that act on the $\beta 3$-adrenoceptors in the bladder and relax, and on the a1-adrenoceptors in the bladder base and urethra to make the urinary storage possible by eliciting contraction of the internal sphincter of urethra through inhibition of the parasympathetic pathway (Andersson, 1993; Andersson and Arner, 2004; Keast et al., 1990).

\section{Somatic nerves}

The motor neurons of the external sphincter of urethra are located in Onuf's (Onufrowicz's) nucleus along the lateral side of the sacral (S2-S4) ventral horn. (Thor and de Groat, 2010; Thor and Donatucci, 2004). They also have dendritic bundles that project laterally toward the lateral funiculus, posteriorly toward the intermediate substance, and posteromedially toward the central canal. They transmit neural impulses to some pelvic floor muscles in addition to the pudendal nerve branches (Barber et al., 2002; de Groat et al., 2001; Pierce et al., 2003; Thor and de Groat, 2010). The neuroanatomical distribution of the efferent and afferent components of urinary storage and micturition reflex are shown. (Fig. 2) The left side depicts the efferent component and the right side presents the afferent component. In the human body, however, these two components are located on both sides and overlap with each other.

\section{Afferent innervation}

The axons of the afferent neurons that are present in the pelvic nerves, hypogastric nerves, and pudendal nerves transmit sensory information from the lower urinary tract system to secondary neurons in the lumbosacral spinal cord (de Groat, 1986; Jänig and Morrison, 1986; Yoshimura and de Groat, 1997). The primary afferent neurons originate from the dorsal root ganglia (DRG) of the sacrum and enter the spinal cord to run up and down in Lissauer's tract. The afferent distribution of hypogastric nerves originates from the DRG of the lumbar cord (Nadelhaft et al., 1980; Thor et al., 1989).

The afferent $A \delta$ nerve fibers in detrusor muscle react to distension and contraction of the bladder and transmit information about bladder filling. The critical values at which $A \delta$ nerve fibers become

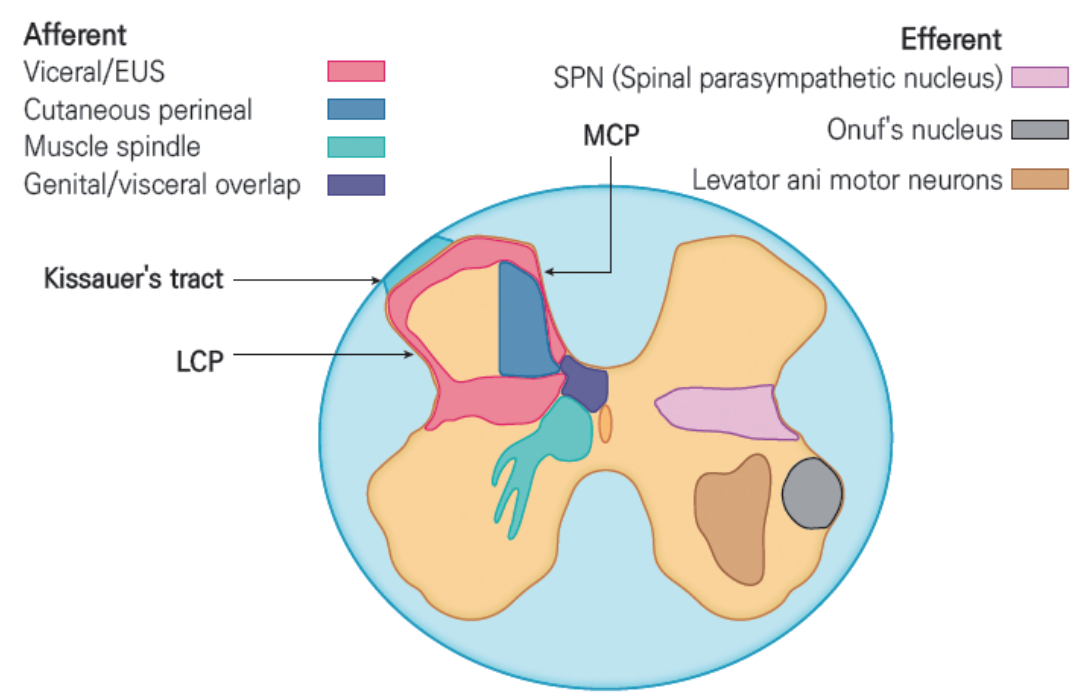

Fig. 2. Cross-sectional diagram of the sacrum. EUS, external urethral sphincter; MCP, medial collateral projection; LCP, lateral collateral projection. 
activated are $5-15 \mathrm{mmH}_{2} \mathrm{O}$, corresponding to the bladder pressures at which humans first feel a sensation of bladder filling. The sensation of bladder volume is conveyed through bladder tension receptors, which specifically detect bladder filling. The afferent impulses that occur during bladder contraction have important reflex functions and reinforce the maintenance of detrusor muscle contraction. The afferent nerves that react to the distension and contraction of the bladder, also known as "in series" tension receptors, have been found in the pelvic nerves and hypogastric nerves in cats and mice (Floyd et al., 1976; Iggo, 1955; Morrison, 1997).

The afferent $\mathrm{C}$ nerve fibers in the mucosa of the bladder are vol- ume receptors that react to bladder filling. A large number of afferent $C$ nerve fibers of the bladder in mice are known to be volume receptors that are sensitive to stretching of the bladder mucosa and non-reactive to contraction of the bladder, with properties distinct from those of tension receptors. Unlike $A \delta$ nerve fibers, afferent $C$ nerve fibers in the mucosa muscularis of the bladder are generally inactive in normal situations. Therefore, they are referred to as mechanoinsensitive or silent $\mathrm{C}$ fibers (Häbler et al., 1990). C nerve fibers are potentially nociceptive to bladder distension and known to be reactive to high concentrations of potassium, low $\mathrm{pH}$, high osmotic pressure, and stimulants such as cap-

Table 1. Properties of afferent nerve fibers in the bladder

\begin{tabular}{|c|c|c|c|}
\hline Nerve fiber & Location & Function & Change caused by inflammation \\
\hline Aঠ nerve fiber (myelinated axon) & Smooth muscle & Detects bladder filling (bladder tension receptor) & $\begin{array}{l}\text { Reduced threshold for pressure: increased reactions to small } \\
\text { changes in pressure }\end{array}$ \\
\hline C nerve fiber (unmyelinated axon) & Mucosa & $\begin{array}{l}\text { Reacts to bladder filling (bladder volume stretch } \\
\text { receptor) }\end{array}$ & $\begin{array}{l}\text { Reduced threshold for changes in volume: increased reactions } \\
\text { to small volume changes }\end{array}$ \\
\hline C nerve fiber (unmyelinated axon) & Muscularis mucosa & $\begin{array}{l}\text { Afferent nerve fiber potentially nociceptive to } \\
\text { bladder distension }\end{array}$ & $\begin{array}{l}\text { Changes into a sensitive mechanoreceptor in response to } \\
\text { inflammatory reactions and forms an afferent pathway with } \\
\text { new functions }\end{array}$ \\
\hline
\end{tabular}

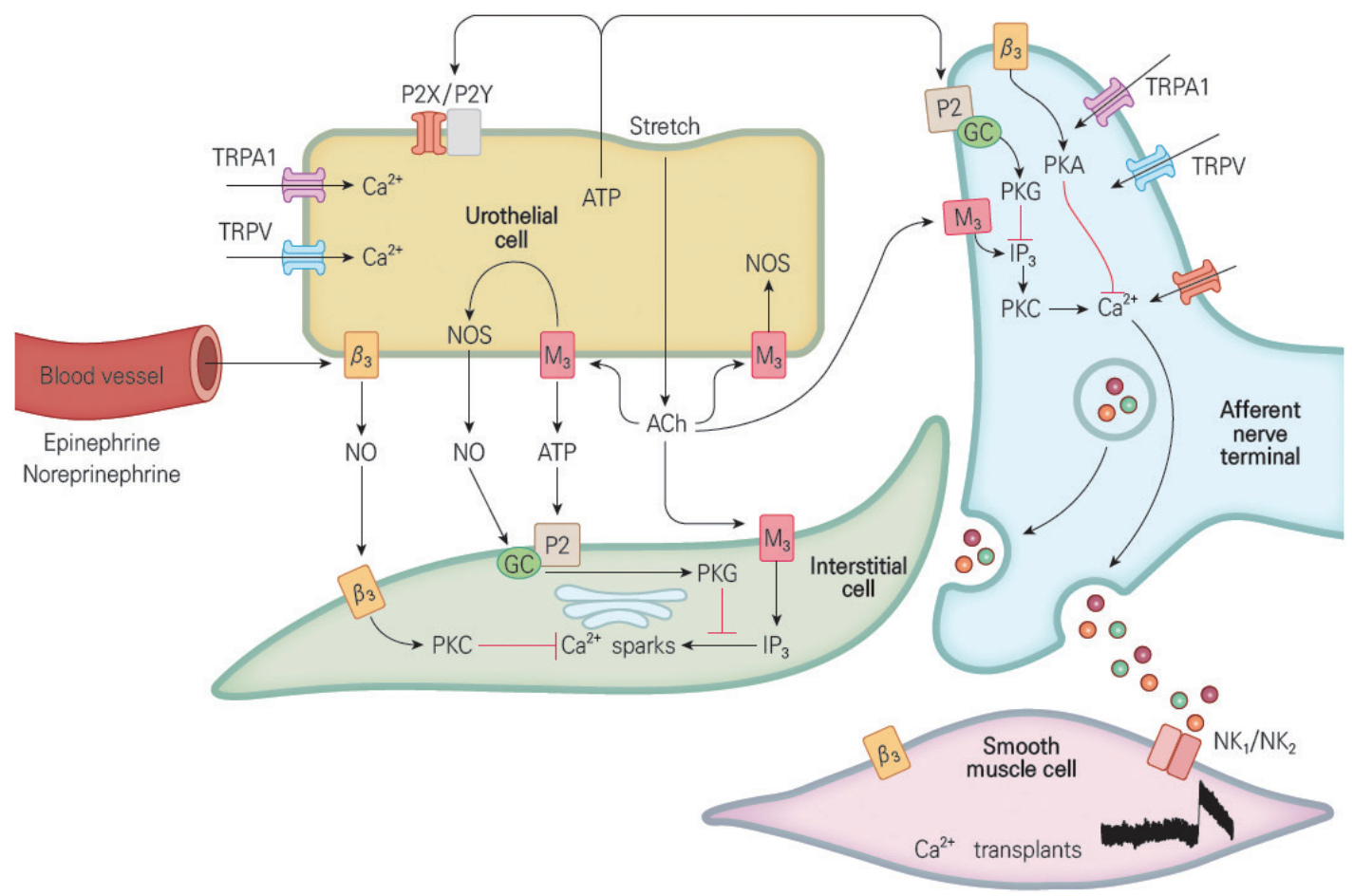

Fig. 3. Interactions among urothelial cells, afferent nerves, interstitial cells, smooth muscle cells, and blood vessel cells in the bladder. ATP, adenosine 5'-triphosphate; P2X, purinergic receptor 2X; P2Y, purinergic receptor 2Y; TRPA, transient receptor potential ankyrin; TRPV, transient receptor potential vanilloid; NO, nitric oxide; NOS, nitric oxide synthase; ACh, acetylcholine; PKA, protein kinase A; PKC, protein kinase C; PKG, protein kinase G; IP3, inositol-1,4,5-trisphosphate; $\beta 3$, beta-3-adrenoceptor; M3, muscarinic acetylcholine type-3 receptor; GC, glucocorticoid; NK1/2, natural killer type 1/2. 
saicin or noxious chemical stimuli (Fall et al., 1990; Häbler et al., 1990; McMahon and Abel, 1987) (Table 1).

The afferent nerve fibers are distributed to all parts of the urethra, including the urothelium, the nerve plexus beneath the urothelium, and around the blood vessels between muscle fibers, to control the function of the lower urinary tract (Hökfelt et al., 1978; Warburton and Santer, 1994). The rhabdosphincter surrounding the urethra is governed by very sparse afferent nerves that are mainly confined to the nerve bundles that run between muscle bundles. Governed by markedly specialized tension receptors (muscle spindles) in most striated muscles, they either do not exist or exist at a low density in rhabdosphincters and are governed by myelinated afferent nerves with large diameters in the IA group.

\section{Interactions between the urothelium and afferent nerves}

Although the urothelium was traditionally considered to be a primary barrier, a recent study found that urothelial cells have characteristics similar to sensory neurons, such as nociceptors and mechanoreceptors, and that the urothelium can work as a transmitter of specific sensors and signals as well as a passive barrier (Birder and Andersson, 2013). The expression of various types of receptors and ion channels related to nerves. (Araki et al., 2004; Beckel and Birder, 2012; Chopra et al., 2008; Kullmann et al., 2011; Uta et al., 2019; Yamada et al., 2009) The urothelium reacts to local chemical and mechanical stimuli and transmits chemical signals to the afferent nerves of the bladder, which deliver information to the central nervous system to regulate the activity of the afferent nerves responsible for bladder sensation (Fig. 3).

\section{THE CENTRAL NERVOUS SYSTEM OF THE LOWER URINARY TRACT}

The central nervous system, which consists of the brain and spinal cord, is home to two micturition control centers and three nerve nuclei. A close look at the spinal cord reveals that the sacrum contains the primary micturition center, the SPN, which was mentioned above, and Onuf's nucleus, which controls the rhabdosphincter. In the thoracolumbar cord, there is another nerve nucleus (sympathetic nervous system) involved in urinary storage, and if it is stimulated, the bladder becomes relaxed and the bladder neck closes. The brain stem, which is located in the lowest part of the brain, is a collective term for the midbrain, pons, and medulla oblongata. Of these, the pons contains the pontine micturition center (PMC), which is the secondary micturition center that sends signals to stop bladder relaxation and induce sphincter relaxation when it is time to micturate. The cerebrum, which is the uppermost part, is known to send signals that inhibit the micturition reflex. With developments in functional human brain imaging and through studies in which neurotrophic viruses such as pseudorabies, the studies revealed that there are four basic components in the circuit that controls micturition as shown in Fig. 4: primary afferent nerves, spinal efferent nerves, spinal intermediate nerves, and neurons of brain nerves, which activate or control spinal intermediate nerves and spinal reflex. The brain regions labeled by virus transport include the PMC, cerebral cortex, periventricular nucleus, medial preoptic area, and ventricular nucleus. Synaptic input to the hypothalamus, periaqueductal gray (PAG) matter, locus ceruleus, subcoeruleus, red nucleus, raphe nucleus, A5 noradrenergic cell group, and upper spinal neurons can send signals to spinal preganglionic neurons or spinal interneurons (Fowler et al., 2008).

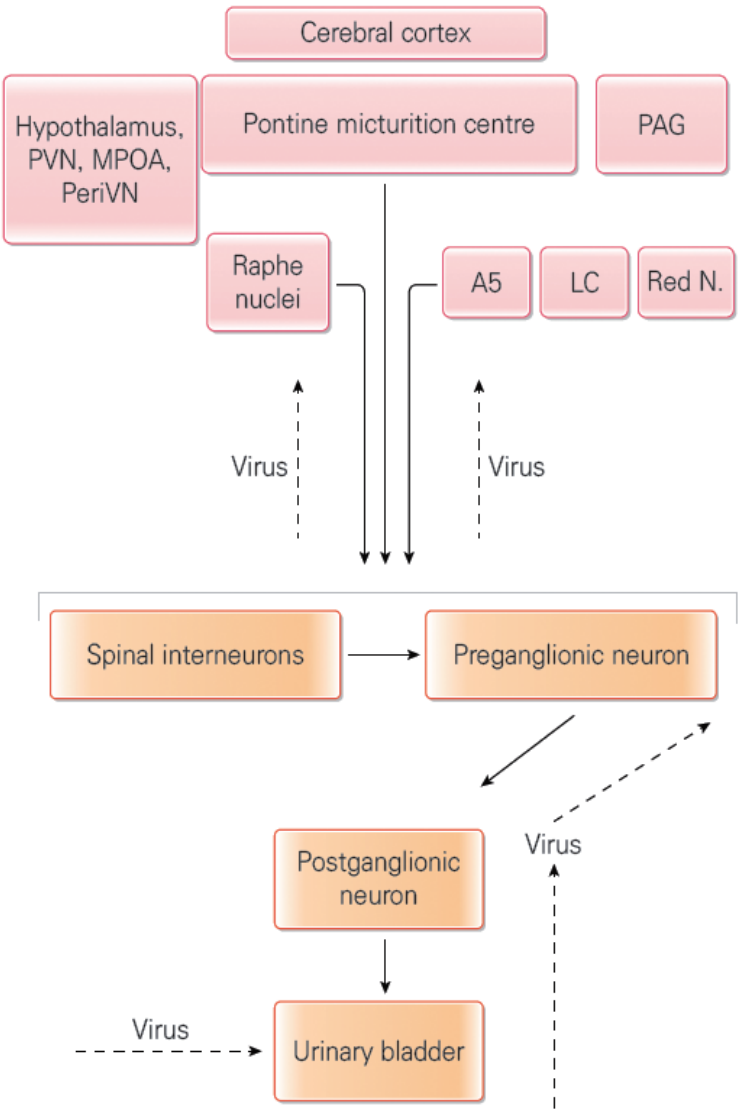

Fig. 4. Connections between the spinal cord and brain areas involved in micturition control. PVN, paraventricular nucleus of the hypothalamus; MPOA, medial preoptic area; PeriVN, periventricular nucleus; PAG, periaqueductal gray; A5, type of pontine noradrenergic cell group; LC, locus coeruleus; Red N, red nucleus. 


\section{Spinal cord}

The afferent pathway in the spinal cord ends in the second-order interneuron, which conveys information to the cerebrum or preganglionic nerves and other areas of the spinal cord that include the motor nuclei. Electroneurological and neuroanatomic studies have found that the interneurons of the lower urinary tract exist in the same area of the spinal cord that receives afferent information from the bladder (Birder and de Groat, 1993; de Groat et al., 1981; de Groat et al., 1996; McMahon and Morrison, 1982a; McMahon and Morrison, 1982b). The afferent nerve fibers of the EUS very closely overlap with the projection area of the afferent nerve fibers of the pelvic nerves, which innervate the bladder and urethra. The dendrites of EUS motor neurons and the dendrites of preganglionic parasympathetic neurons are similar to each other, and glutamic acid acts as an excitatory neurotransmitter in this pathway.

Micturition reflexes can be modified by the mechanism of interneurons activated by afferent stimuli that originate from the skin and striated muscles, as well as by neurotransmitters from internal organs (de Groat, 1975; de Groat et al., 1981; McMahon and Morrison, 1982a; Morrison et al., 1995; Yoshimura and de Groat, 1997). Stimulation of afferent nerve fibers from different organs (the anus, colon, and rectum, and the pudendal nerves in the cervix, perineum, and penis) can inhibit the activity of sacral interneurons induced by bladder distension (de Groat et al., 1981).

\section{Brain stem: pons and PAG}

Above the bladder and urethral sphincter, which are the end organs, is the PMC, the center that controls the bladder and urethral sphincter. The neurons of the PMC and multiple neuronal groups in the upper spinal cord are connected to each other, and these connections coordinate micturition (Fig. 5). Although the pathway in humans is not clear, brain imaging research shows that there is increased blood flow in the pons during micturition (Blok et al., 1997). The dorsal pontine tegmentum has been established as the fundamental control center for micturition. It was first described by Barrington (1921), and the Barrington nucleus is referred to as the $\mathrm{M}$ region due to its location in the PMC.

The neurons of the PMC are directly connected to the sacral preganglionic parasympathetic neurons as well as the gamma-aminobutyric acid neurons in the sacral dorsal commissure area (Blok and Holstege, 1997; Blok et al., 1997). While the former conveys excitation to the bladder, the latter is considered to be important in the transmission of inhibitory reactions to motor neurons in the EUS. As a result of these mutual connections, the PMC promotes

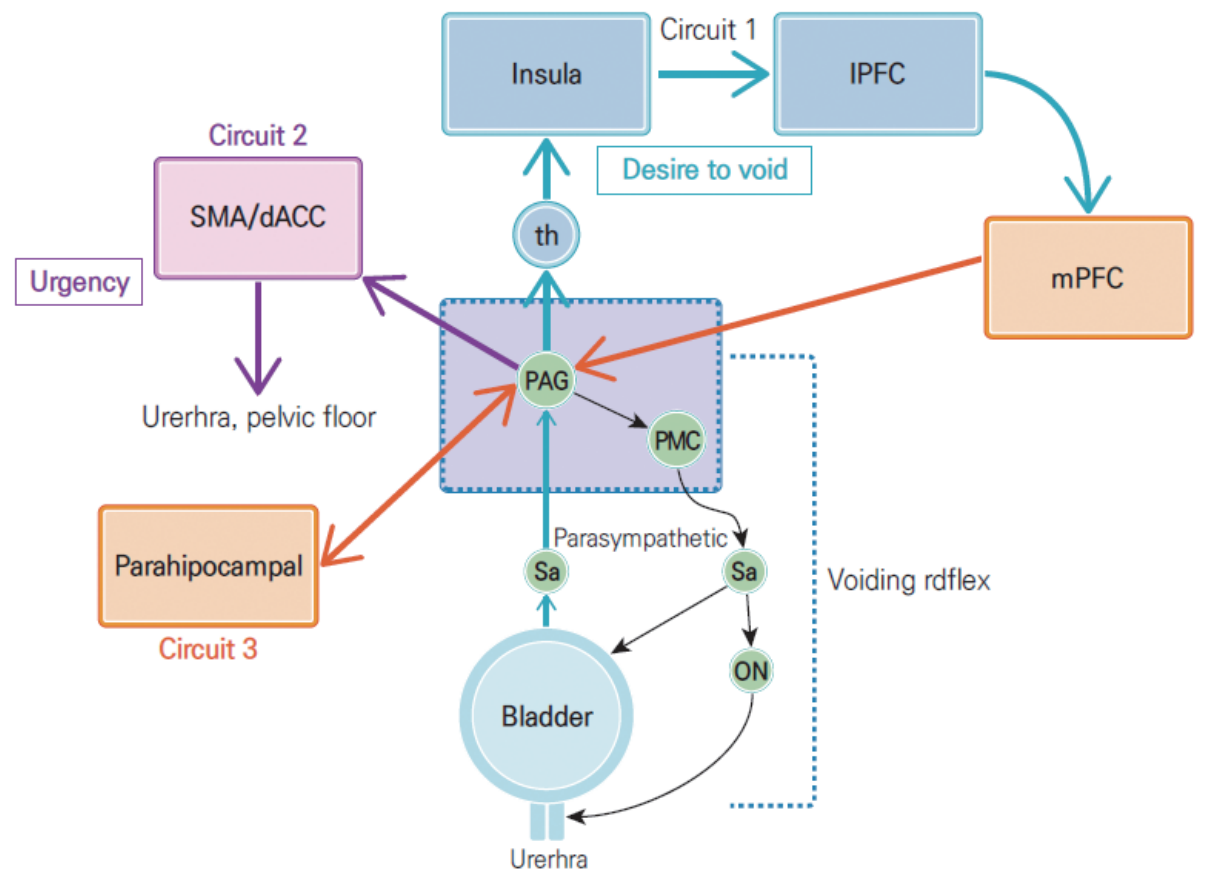

Fig. 5. Simple model for the control system of the lower urinary tract. The micturition reflex (purple) and three types of pathways (orange, light purple, and blue). PAG, periaqueductal gray; PMC, pontine micturition center; th: thalamus; $\mathrm{mPFC}$, medial prefrontal cortex; IPFC, lateral prefrontal cortex; SMA, supplementary motor area; dACC, dorsal anterior cingulate cortex. 
the coordination of the bladder and sphincter. If the pons is stimulated by bladder filling, it sends signals downwards to stop bladder relaxation and induce relaxation of the urethral sphincters at the same time so that the bladder may contract.

The PAG occupies an important position between the cerebrum and bladder to decide micturition (Prabhakar et al., 2019). The switch between urine storage and voiding in the lower urinary tract is mediated by the spinobulbospinal reflex under normal conditions (Fowler et al., 2008; Griffiths and Fowler, 2013). While the bladder is being filled, activity occurs in the pons, especially in the PAG area, until the afferent signals in the bladder surpass a specific threshold value. Micturition reflexes occur if there is no control over them. That is, bladder contraction and micturition start when the PMC is activated and the urethral sphincter is relaxed. Moreover, the PAG may exchanges bladder-related signals with the other parts of the brain, since the parahippocampal cortex is close to an amygdaloid body, it is thought to be involved in the aspect of emotional "safety" related to micturition (Kim et al., 2020).

\section{The cerebrum: regulatory mechanisms identified through human brain imaging research}

Brain imaging studies using single-photon emission computed tomography, positron emission tomography, and functional magnetic resonance imaging have been conducted on the brain areas involved in micturition control (Fukuyama et al., 1996; Karmonik et al., 2019; Lane and Wager, 2009). In essence, the cerebrum, which is the uppermost component of the nervous system, acts to inhibit bladder contraction. Afferent stimulation of the bladder and urethra while urine is being stored in normal people in good health is transmitted to the PAG and detected in the insular lobe to form the sensation for the normal urge to void. These processes are monitored by the anterior cingulate gyrus. The micturition reflex is continuously inhibited until the decision to void is made in the prefrontal lobe in the prefrontal cortex or limbic system. In patients with urge incontinence, weak reactivity or inactivity is observed, which can cause urge incontinence by inducing bladder control defects of the upper spinal cord. Moreover, increased reactivity in the anterior cingulate gyrus is correlated with abnormal afferent nerve stimulation in the bladder and the loss of control in other areas of the brain and may be related to urinary urgency. Thus, infants, children whose brain has not fully matured, and older people with neurodegenerative diseases become vulnerable to urge incontinence due to declining nerve function (Griffiths and Tadic, 2008; Tadic et al., 2012; Tadic et al., 2013).

\section{PHYSIOLOGY OF URINARY CONTINENCE AND MICTURITION REFLEX}

While the bladder is being filled in both humans and animals, the pressure in the bladder remains at a relatively low and consistent level until it reaches the threshold volume to induce micturition. Before the bladder is filled enough, weak afferent signals from the bladder continue to stimulate the sympathetic nervous system and sacral nerve so that urine can continue to be stored. As a result, the bladder is actively relaxed, and the urethral sphincters remain contracted. When the bladder becomes full, strong afferent signals of the bladder are transmitted to the pons, which is the secondary micturition center. The pons stops the rhabdosphincter from contracting through the somatic nervous system through parasympathetic stimulation of the primary micturition center, causing the bladder to contract. Moreover, it ceases the stimulation of the sympathetic nerve system to stop bladder relaxation and open the bladder neck (smooth urethral sphincter). This is the basic mechanism of contraction and relaxation of the bladder and urethral sphincter. To summarize, the urinary system works mainly through the sympathetic nervous system to store urine and through the parasympathetic nervous system to void it.

A number of the reflex circuits formed in the brain and spinal cord to control the function of the lower urinary tract are composed of simple on-off switch circuits, which maintain the coordinated interactions between the bladder and urethra (Fig. 6, Table 2). Some reflexes are responsible for promoting micturition, and the individual reflexes may be connected to one other to form a complex feedback mechanism. For example, the guarding reflex of the EUS, which causes the sphincter to contract when the bladder is full, can activate the afferent nerve fibers of the sphincter, which induce inhibition of the parasympathetic pathway entering the bladder. Thus, changes in such reflex mechanisms may lead to neurogenic dysfunction of the lower urinary tract. Direct stimulation of these reflexes by electrical stimulation of sacral nerve roots contributes to therapeutic effects through the control of sacral nerve roots (Cong et al., 2019; de Groat et al., 2001; Kavia et al., 2010).

\section{The reflex circuit that regulates urinary storage}

During the urinary storage phase, weak afferent signals of the bladder are produced consistently. These signals do not ascend to high level of nerve systems and remain around the spinal cord to induce contraction of the internal urethral sphincter and active relaxation of the bladder by stimulating the sympathetic nerves of 


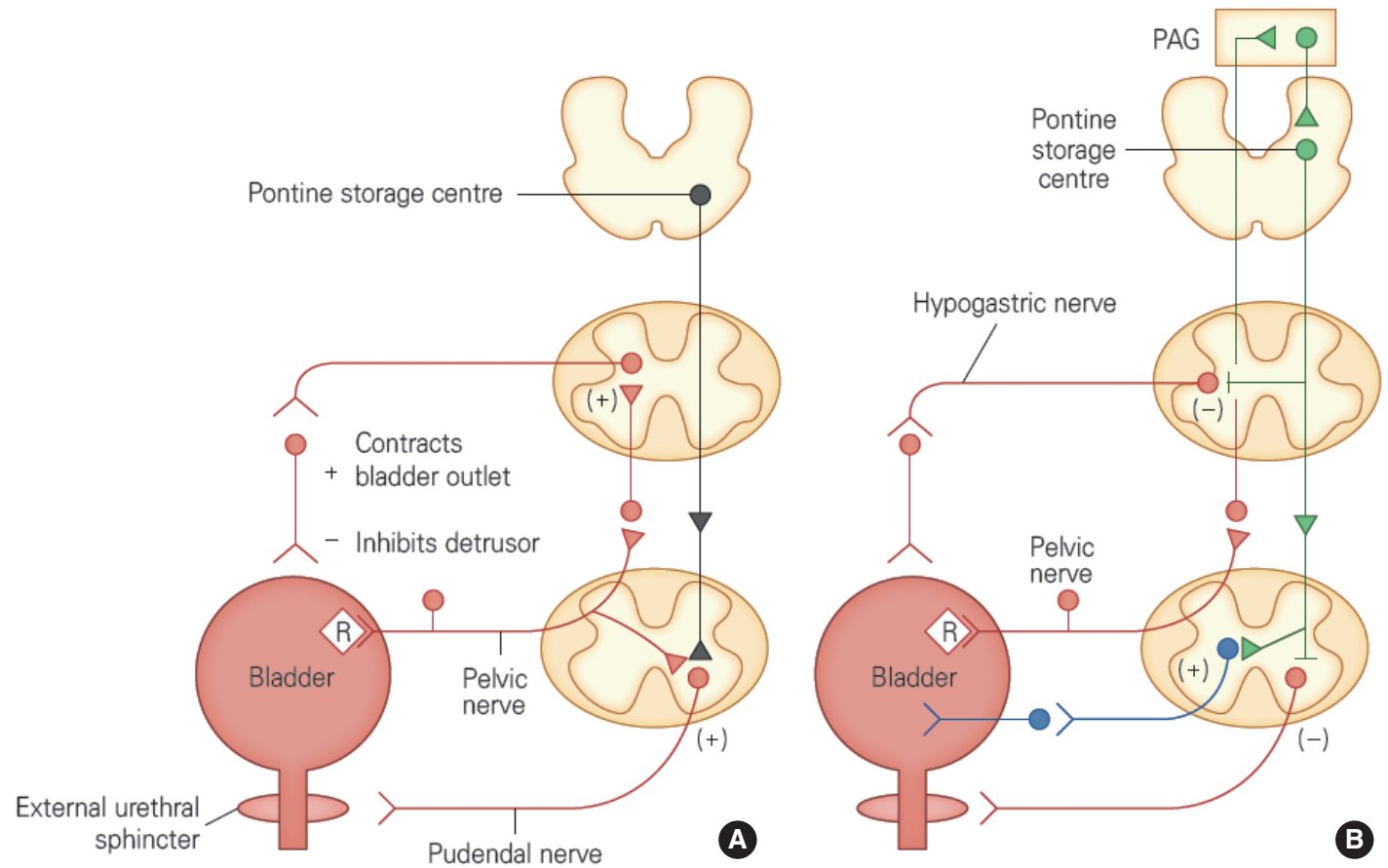

Fig. 6. Types of micturition reflexes. (A) Urinary storage reflex. Distension of the bladder while it is being filled with urine activates low-level afferent nerves in the bladder, resulting in stimulation of the sympathetic nerves traveling to the bladder outlet (bladder base and urethra) and the pudendal nerves traveling to the external urethral sphincter. These reactions caused by the spinal reflex pathway are called "protective reflexes" and make urinary continence possible. In addition, sympathetic nerves inhibit nerve conduction in the detrusor and bladder ganglia. (B) Micturition reflex. Activation of the afferent nerves in the bladder occurs when micturition starts, stimulating the pontine micturition center (PMC) and inhibiting spinal protective reflexes. Moreover, the PMC stimulates the parasympathetic nerves running to the bladder and internal urethral sphincter. Maintenance of micturition reflexes depends on the afferent input from the spinal cord passing through the PAG before reaching the PMC (Fowler et al., 2008). PAG, periaqueductal gray.

Table 2. Reflexes of the lower urinary tract

\begin{tabular}{|c|c|c|c|}
\hline Afferent pathways & & Efferent pathways & Central pathway \\
\hline Urinary storage phase & $\begin{array}{l}\text { Activation of low-level afferent nerves } \\
\text { in the bladder (pelvic nerves) }\end{array}$ & $\begin{array}{l}\text { Contraction of the external urethral sphincter (somatic nerves) } \\
\text { Contraction of the internal urethral sphincter (sympathetic nerves) } \\
\text { Inhibition of the detrusor (sympathetic nerves) } \\
\text { Inhibition of conduction in bladder ganglia (sympathetic nerves) } \\
\text { Inactivation of the sacral parasympathetic pathway }\end{array}$ & Spinal reflex \\
\hline Micturition phase & $\begin{array}{l}\text { Activation of high-level afferent nerves } \\
\text { in the bladder (pelvic nerves) }\end{array}$ & $\begin{array}{l}\text { Inhibition of external urethral sphincter activation } \\
\text { Inhibition of the sympathetic pathway } \\
\text { Activation of the parasympathetic pathway in the bladder } \\
\text { Activation of the urethral parasympathetic pathway }\end{array}$ & Spinal medullary spinal reflex \\
\hline
\end{tabular}

the thoracolumbar cord. In addition, these signals stimulate pudendal nerves through somatic nerves to contract the EUS so that urine can be continent. The bladder-to-sympathetic nervous system reflexes work as negative feedback and contribute to the storage mechanism, which causes the bladder outlet to be blocked and inhibits bladder contraction (de Groat and Theobald, 1976) (Table 2). The activation of the sympathetic nerve reflex on the lower urinary tract is elicited by afferent nerve activity, which is caused by bladder distension (de Groat et al., 1996). These reflex reactions are formed in the lumbosacral cord and can be maintained even if the thoracic cord is damaged. However, if sympathetic ganglia are damaged by retroperitoneal lymph node dissection, the sympathetic nerve mechanism of the bladder, which inhibits bladder contraction.

Increased activity in the electromyogram of the sphincter during bladder filling reflects the increased afferent activity of pudendal nerves and contributes to maintenance of urinary continence by increasing the outlet resistance. Moreover, the motor neurons of 
the EUS are activated by the urethroperineal afferent nerve fibers that exist in pudendal nerves, and these reflexes of the sphincter are formed in the spinal cord. Inhibition of the reflex activity in the EUS while voiding depends partially on the mechanism of the upper sacral cord. To summarize, these inhibitory mechanisms are either weak or nonexistent in people with long-term spinal cord disorders, and contraction of the bladder and the sphincter (e.g., detrusor sphincter dyssynergia) occurs simultaneously, as a result (Blaivas, 1982; Kim et al., 2020; Rossier and Ott, 1976).

\section{The reflex circuit that regulates micturition}

Urinary storage phase can be converted to micturition phase either involuntarily (reflexively) or voluntarily. When the amount of urine exceeds the threshold for voiding, afferent activity from the tension receptors in the bladder increases strongly and is immediately conveyed to the PMC. When the PMC is stimulated, it inhibits the activity of both sympathetic nerves and somatic nerves and activates parasympathetic pathways to contract the detrusor muscle. A few seconds after relaxation of the urethral sphincter, the pressure in the bladder increases, which leads to the micturition. Relaxation of the urethral smooth muscles during voiding is mediated by the removal of excitatory inputs to the urethra, which triggers the release of nitric oxide, an inhibitory neurotransmitter, in the urethra due to the activation of parasympathetic nerves (Andersson, 1993; Bennett et al., 1995). Moreover, secondary reflexes caused by the flow of urine through the urethra promote voiding in turn (Jung et al., 1999). The parasympathetic nerve flow to the detrusor muscle and urethra is organized into the central part in a more complicated way and related to the spinobulbospinal pathway, which passes through the PMC. In addition, there are nerve circuits that work locally. If one contracts the pelvic floor consciously when an urge to void is felt, bladder contraction can be inhibited (guarding reflex) (Lee et al., 2017). This loss of bladder contraction is due to the local reflex arc.

\section{THE CENTRAL PATHWAY THAT REGULATES THE MICTURITION REFLEX}

The effect of the cerebrum on micturition is regulated by multiple pathways. Various cortical regions related to the lower urinary tract were discovered through studies using the neurotrophic pseudorabies virus (Nadelhaft and Vera, 1996; Sugaya et al., 1998; Vizzard et al., 1995). The effect of the cortex on micturition is regulated by pathways projecting from the prefrontal cortex and insular cortex to the PMC or pathways projecting to the hypothal- amus and extrapyramidal system. It has been revealed that voluntary control of micturition is accomplished by the connection between the septal area of the frontal lobe and the preoptic area of the hypothalamus, as well as by the connection between the paracentral lobule and brain stem. If inhibitory regulation from the cerebrum is removed, bladder activity is increased. Imaging studies of the human cerebrum have shown that the frontal lobe and the frontal part of the cingulate gyrus are involved in micturition control and that micturition is largely controlled by the right side of the brain (Blok et al., 1997; Fukuyama et al., 1996). When one fails to micturate, there is increased blood flow in the right inferior frontal gyrus, and when one holds urine, blood flow in the right inferior frontal gyrus decreases. This finding suggests that the human brain stem has a special nucleus that is responsible for micturition control and that the regions of the cerebral cortex and brain stem that are involved in micturition exist mainly on the right side. In the results of clinical analyses of urinary frequency and urinary urgency, patients with left hemiplegia complained of urinary urgency more often than patients with right hemiplegia.

Generally, patients with lesions in the basal ganglia or thalamus have a normally-functioning urethral sphincter. When these patients contract the rhabdosphincter voluntarily and when noninhibitory detrusor contractions occur, abnormal micturition reflexes may disappear or decrease significantly. However, patients with lesions in the cerebral cortex or internal capsule caused by cerebral infartion cannot contract the rhabdosphincter strongly due to serious abnormalities in the cerebral-to-corticospinal circuitry that is needed for voluntary contractions of the rhabdosphincter.

\section{CLINICAL SIGNIFICANCE}

Generally, under normal circumstances, UMNs maintain a neurophysiological state that inhibits LMNs. Thus, urinary retention/ stress incontinence/poor bladder compliance may be induced as a result of lower spinal cord injury or peripheral nerve injury, which causes LMN dysfunction. Detrusor sphincter dyssynyergia, autonomic dysreflexia, and detrusor overactivity may occur in response to UMN dysfunction or cerebral injuries (Chancellor et al., 2020). The problems that can arise as a result of cerebral injuries that cause sensory neuron dysfunction, include sensory unawareness, which refers to failure to sense bladder filling and urine flow in the urethra, urinary retention, which is caused by failure to micturate due to inability to relax the EUS in consequence of decision-making disorder, enuresis and nocturia, which occur due to inability to determine the time and place for micturition, and 
urge incontinence (Cong et al., 2019). As such, innervation of the lower urinary tract can be summarized from several perspectives. The clinical and treatment principles for neurourologic diseases that we should observe are first and foremost, the prevention of autonomic nervous reflex dysfunction, followed by the improvement of storage symptoms and micturition symptoms (Uta et al., 2019; Uta et al., 2020a; Uta et al., 2020b).

\section{DIRECTIONS OF NEUROUROLOGICAL RESEARCH}

In disease conditions accompanied by the aging process or a neurological disorder, inhibitory regulation of the cerebrum is weakened due to unnecessary activity of the micturition center. Enuresis or accompanied lower urinary tract symptoms are mostly thought to occur due to spinal reflexes that are not inhibited in the cerebrum. Thus, if external local effects that influence the activation of the micturition center of the brain can be controlled, this pathological activation can be regulated and become the target of treatment. The verification of this possibility is expected to be helpful for improving our understanding of diseases accompanied by micturition disorders, such as aging-related conditions and degenerative brain diseases, as well as for the development of medicines for these disorders. Urodynamic study is used to determine the phenotype and etiology of dysfunction when diagnosing and treating patients with lower urinary tract dysfunction, including neurogenic dysfunction. These tests allow myogenic, urotheliogenic, and neurogenic causes to be distinguished, and the damaged regions can also be explored in cases of neurogenic dysfunction. The first step in treatment is finding and regulating controllable pathophysiological factors related to the patient's condition. However, a limitation of existing treatment methods is that they are applied only to peripheral treatment targets. Therefore, as mentioned above, if an integrated research methodology to explore factors that disrupt central inhibition in the micturition center of the brain is found, it could be used to discover various targets for regulation depending on the dysfunction. In addition, a method to distinguish between the phenotypes of neurological bladder diseases must also be found.

\section{NEUROUROLOGICAL RESEARCH PERSPECTIVES}

Previous studies, including several functional imaging studies, have found that there is a specific region (the micturition center) of the brain containing specific neurons or neuronal groups that are involved in micturition. Animal studies have revealed how the activated or inactivated state of a specific region correlates with normal and disordered micturition. However, the basic mechanism explaining these phenomena has not been established, which is why targeted methods to control these changes do not yet exist. Neurourological observations and testing to discover how specific neurotransmitters and neuropeptides in the cerebrum impact the activation and inhibition of synapse connections involved in micturition control will be essential components of research in neurourological studies aiming to elucidate the basic mechanisms. Moreover, it is necessary to monitor in real time how specific neurons are involved in micturition and how specific physiological conditions (aging, sleep, and learning) or specific pathological conditions (spinal cord damage, cerebral damage, and degenerative brain diseases) influence micturition by activating or inactivating neurons in specific regions, and to investigate whether a specific treatment affects neuronal activity and how this influence is correlated with changes in micturition.

\section{CONFLICT OF INTEREST}

No potential conflict of interest relevant to this article was reported.

\section{ACKNOWLEDGMENTS}

The authors received no financial support for this article.

\section{REFERENCES}

Andersson KE. Pharmacology of lower urinary tract smooth muscle and penile erectile tissues. Pharmacol Rev 1993;45:253-308.

Andersson KE, Arner A. Urinary bladder contraction and relaxation: physiology and pathophysiology. Physiol Rev 2004;84:935-986.

Andersson KE, Wein AJ. Pharmacology of the lower urinary tract: basis for current and future treatments of urinary incontinence. Pharmacol Rev 2004;56:581-631.

Araki I, Du S, Kamiyama M, Mikami Y, Matsushita K, Komuro M, Furuya Y, Takeda M. Overexpression of epithelial sodium channels in epithelium of human urinary bladder with outlet obstruction. Urology 2004; 64:1255-1260.

Barber MD, Bremer RE, Thor KB, Dolber PC, Kuehl TJ, Coates KW. Innervation of the female levator ani muscles. Am J Obstet Gynecol 2002; 187:64-71. 
Barrington FJF. The relation of the hindbrain to micturition. Brain 1921; 44:23-53.

Beckel JM, Birder LA. Differential expression and function of nicotinic acetylcholine receptors in the urinary bladder epithelium of the rat. J Physiol 2012;590:1465-1480.

Bennett BC, Kruse MN, Roppolo JR, Flood HD, Fraser M, de Groat WC. Neural control of urethral outlet activity in vivo: role of nitric oxide. J Urol 1995;153:2004-2009.

Birder LA, Andersson KE. Urothelial signaling. Physiol Rev 2013;93:653680.

Birder LA, de Groat WC. Induction of c-fos expression in spinal neurons by nociceptive and nonnociceptive stimulation of LUT. Am J Physiol 1993;265:R326-333.

Blaivas JG. The Neurophysiology of micturition: a clinical study of 550 patients. J Urol 1982;127:958-963.

Blok BF, Holstege G. Ultrastructural evidence for a direct pathway from the pontine micturition center to the parasympathetic preganglionic motoneurons of the bladder of the cat. Neurosci Lett 1997;222:195-198.

Blok BF, Willemsen AT, Holstege G. A PET study on brain control of micturition in humans. Brain 1997;120:111-121.

Burnstock G. Purine-mediated signalling in pain and visceral perception. Trends Pharmacol Sci 2001;22:182-188.

Chancellor MB, Bartolone SN, Lamb LE, Ward E, Zwaans BMM, Diokno A. Underactive bladder; review of progress and impact from the international CURE-UAB initiative. Int Neurourol J 2020;24:3-11.

Chopra B, Gever J, Barrick SR, Hanna-Mitchell AT, Beckel JM, Ford AP, Birder LA. Expression and function of rat urothelial P2Y receptors. Am J Physiol Renal Physiol 2008;294:F821-F829.

Cong H, Liao L, Wang Y, Zhao L, Wang Z, Fu G, Chen G. Effects of acute sacral neuromodulation at different pulse widths on bladder overactivity in pigs. Int Neurourol J 2019;23:109-115.

de Groat WC. Integrative control of the lower urinary tract: preclinical perspective. Br J Pharmacol 2006;147(Suppl 2):S25-S40.

de Groat WC. Nervous control of the urinary bladder of the cat. Brain Res 1975;87:201-211

de Groat WC. Spinal cord projections and neuropeptides in visceral afferent neurons. Prog Brain Res 1986;67:165-187.

de Groat WC, Fraser MO, Yoshiyama M, Smerin S, Tai C, Chancellor MB, Yoshimura N, Roppolo JR. Neural control of the urethra. Scand J Urol Nephrol Suppl 2001;207:35-43; discussion 106-125.

de Groat WC, Nadelhaft I, Milne RJ, Booth AM, Morgan C, Thor K. Organization of the sacral parasympathetic reflex pathways to the urinary bladder and large intestine. J Auton Nerv Syst 1981;3:135-160.

de Groat WC, Theobald RJ. Reflex activation of sympathetic pathways to vesical smooth muscle and parasympathetic ganglia by electrical stim- ulation of vesical afferents. J Physiol 1976;259:223-237.

de Groat WC, Vizzard MA, Araki I, Roppolo J. Spinal interneurons and preganglionic neurons in sacral autonomic reflex pathways. Prog Brain Res 1996;107:97-111.

Fall M, Lindström S, Mazieres L. A bladder-to-bladder cooling reflex in the cat. J Physiol1990;427:281-300.

Floyd K, Hick VE, Morrison JFB. Mechanosensitive afferent units in the hypogastric nerve of the cat. J Physiol 1976;259:457-471.

Fowler CJ, Griffiths D, de Groat WC. The neural control of micturition. Nat Rev Neurosci 2008;9:453-466.

Fukuyama H, Matsuzaki S, Ouchi Y, Yamauchi H, Nagahama Y, Kimura J, Shibasaki H. Neural control of micturition in man examined with single photon emission computed tomography using 99mTc-HMPAO. Neuroreport 1996;7:3009-3012.

Griffiths D, Tadic SD. Bladder control, urgency, and urge incontinence: evidence from functional brain imaging. Neurourol Urodyn 2008;27: 466-474.

Griffiths DJ, Fowler CJ. The micturition switch and its forebrain influences. Acta Physiol (Oxf) 2013;207:93-109.

Häbler HJ, Jänig W, Koltzenburg M. Activation of unmyelinated afferent fibres by mechanical stimuli and inflammation of the urinary bladder in the cat. J Physiol 1990;425:545-562.

Hökfelt T, Schultzberg M, Elde R, Nilsson G, Terenius L, Said S, Goldstein M. Peptide neurons in peripheral tissues including the urinary tract: Immunohistochemical studies. Acta Pharmacol Toxicol (Copenh) 1978;43 Suppl 2:79-89.

Iggo A. Tension receptors in the stomach and the urinary bladder. J Physio 1955;128:593-610.

Jänig W, Morrison JFB. Functional properties of spinal visceral afferents supplying abdominal and pelvic organs, with special emphasis on visceral nociception. Prog Brain Res 1986;67:87-114.

Jung SY, Fraser MO, Ozawa H, Yokoyama O, Yoshiyama M, De Groat WC, Chancellor MB. Urethral afferent nerve activity affects the micturition reflex; implication for the relationship between stress incontinence and detrusor instability. J Urol 1999;162:204-212.

Karmonik C, Boone T, Khavari R. Data-driven machine-learning quantifies differences in the voiding initiation network in neurogenic voiding dysfunction in women with multiple sclerosis. Int Neurourol J 2019;23:195-204.

Kavia R, Dasgupta R, Critchley H, Fowler C, Griffiths D. A functional magnetic resonance imaging study of the effect of sacral neuromodulation on brain responses in women with Fowler's syndrome. BJU Int 2010;105:366-372.

Keast JR, Kawatani M, de Groat WC. Sympathetic modulation of cholinergic transmission in cat vesical ganglia is mediated by alpha 1- and 
alpha 2-adrenoceptors. Am J Physiol 1990;258:R44-R50.

Kim JW, Kim SJ, Park JM, Na YG, Kim KH. Past, present, and future in the study of neural control of the lower urinary tract. Int Neurourol J 2020;24:191-199

Kullmann FA, Downs TR, Artim DE, Limberg BJ, Shah M, Contract D, de Groat WC, Rosenbaum JS. Urothelial beta-3 adrenergic receptors in the rat bladder. Neurourol Urodyn 2011;30:144-150.

Lane RD, Wager TD. The new field of Brain-Body Medicine: what have we learned and where are we headed? Neuroimage 2009;47:1135-1140.

Lee BA, Kim SJ, Choi DK, Kwon O, Na HR, Cho ST. Effects of pelvic floor muscle exercise on urinary incontinence in elderly women with cognitive impairment. Int Neurourol J 2017;21:295-301.

Matsui M, Motomura D, Fujikawa T, Jiang J, Takahashi S, Manabe T, Taketo MM. Mice lacking M2 and M3 muscarinic acetylcholine receptors are devoid of cholinergic smooth muscle contractions but still viable. J Neurosci 2002;22:10627-10632.

Matsui M, Motomura D, Karasawa H, Fujikawa T, Jiang J, Komiya Y, Takahashi S, Taketo MM. Multiple functional defects in peripheral autonomic organs in mice lacking muscarinic acetylcholine receptor gene for the M3 subtype. Proc Natl Acad Sci U S A 2000;97:9579-9584.

McMahon SB, Abel C. A model for the study of visceral pain states: chronic inflammation of the chronic decerebrate rat urinary bladder by irritant chemicals. Pain 1987;28:109-127.

McMahon SB, Morrison JF. Spinal neurones with long projections activated from the abdominal viscera of the cat. J Physiol 1982a;322:1-20.

McMahon SB, Morrison JF. Two group of spinal interneurones that respond to stimulation of the abdominal viscera of the cat. J Physiol 1982b;322: 21-34.

Morrison JF. The physiological mechanisms involved in bladder emptying. Scand J Urol Nephrol Suppl 1997;184:15-18.

Morrison JF, Sato A, Sato Y, Yamanishi T. The influence of afferent inputs from skin and viscera on the activity of the bladder and the skeletal muscle surrounding the urethra in the rat. Neurosci Res 1995;23:195205.

Nadelhaft I, de Groat WC, Morgan C. Location and morphology of parasympathetic preganglionic neurons in the sacral spinal cord of the cat revealed by retrograde axonal transport of horseradish peroxidase. J Comp Neurol 1980;193:265-281.

Nadelhaft I, Vera PL. Neurons in the rat brain and spinal cord labeled after pseudorabies virus injected into the external urethral sphincter. J Comp Neurol 1996; 375:502-517.

Palea S, Artibani W, Ostardo E, Trist DG, Pietra C. Evidence for purinergic neurotransmission in human urinary bladder affected by interstitial cystitis. J Urol 1993;150:2007-2012.

Pierce LM, Reyes M, Thor KB, Dolber PC, Bremer RE, Kuehl TJ, Coates
KW. Innervation of the levator ani muscles in the female squirrel monkey. Am J Obstet Gynecol 2003;188:1141-1147.

Prabhakar AT, Iqbal Ahmed AS, Vijayakrishnan Nair A, Mathew V, Aaron S, Sivadasan A, Alexander M. Neural correlates of urinary retention in lateral medullary infarction. Int Neurourol J 2019;23:205-210.

Rossier AB, Ott R. Bladder and urethral recordings in acute and chronic spinal cord injury patients. Int Urol 1976;31:49-59.

Sugaya K, Ogawa Y, Hatano T, Koyama Y, Miyazato T, Oda M. Evidence for involvement of the subcoeruleus nucleus and nucleus raphe magnus in urine storage and penile erection in decerebrate rats. J Urol 1998; 159:2172-2176.

Tadic SD, Griffiths D, Schaefer W, Murrin A, Clarkson B, Resnick NM. Brain activity underlying impaired continence control in older women with overactive bladder. Neurourol Urodyn 2012;31:652-658.

Tadic SD, Tannenbaum C, Resnick NM, Griffiths D. Brain responses to bladder filling in older women without urgency incontinence. Neurourol Urodyn 2013;32:435-440.

Thor KB, de Groat WC. Neural control of the female urethral and anal rhabdosphincter and pelvic floor muscles. Am J Physiol Regul Integr Comp Physiol 2010;299:R416-R438.

Thor KB, Donatucci C. Central nervous system control of the lower urinary tract: New pharmacological approaches to stress urinary incontinence in women. J Urol 2004;172:27-33.

Thor KB, Morgan C, Nadelhaft I, Houston M, De Groat WC. Organization of afferent and efferent pathways in the pudendal nerve of the female cat. J COmp Neurol 1989;288:263-279.

Uta D, Hattori T, Yoshimura M. Characterization on responsiveness of excitatory synaptic transmissions to $\alpha 1$-adrenoceptor blockers in substantia gelatinosa neurons isolated from lumbo-sacral level in rat spinal cords. Int Neurourol J 2019;23:13-21.

Uta D, Hattori T, Yoshimura M. Differential effects of alpha 1-adrenoceptor antagonists on the postsynaptic sensitivity: using slice patch-clamp technique for inhibitory postsynaptic current in substantia gelatinosa neurons from lumbosacral spinal cord in rats. Int Neurourol J 2020a; 24:127-134.

Uta D, Hattori T, Yoshimura M. Effect of alpha 1-adrnoceptor antagonists on postsynaptic sensitivity in substantia gelatinosa neurons from lumbosacral spinal cord in rats using slice patch-clamp technique for $\mathrm{mE}$ PSC. Int Neurourol J 2020b;24:135-143.

Vizzard MA, Erickson VL, Card JP, Roppolo JR, de Groat WC. Transneuronal labeling of neurons in the adult rat brain and spinal cord after injection of pseudorabies virus into the urethra. J Comp Neurol 1995; 355:629-640.

Warburton AL, Santer RM. Sympathetic and sensory innervation of the urinary tract in young adult and aged rats: A semi-quantitative histo- 
chemical and immunohistochemical study. Histochem J 1994;26:127133.

Yamada T, Ugawa S, Ueda T, Ishida Y, Kajita K, Shimada S. Differential localizations of the transient receptor potential channels TRPV4 and
TRPV1 in the mouse urinary bladder. J Histochem Cytochem 2009;57: 277-287.

Yoshimura N, de Groat WC. Neural control of the lower urinary tract. Int J Urol 1997;4:111-125. 